\title{
DIREITO AGRÁRIO COMO DIREITO DE TERCEIRA DIMENSÃO: CONSIDERAÇÕES TEÓRICAS SOBRE A FUNÇÃO SOCIAL, DOMÍNIO, PROPRIEDADE E POSSE
}

\section{AGRARIAN LAW AS THIRD DIMENSION HUMAN RIGHT: THEORY CONSIDERATIONS ABOUT SOCIAL ROLE, DOMAIN, PROPERTY AND POSSESSION}

\section{RESUMO}

O artigo trata da função social da propriedade como princípio de Direito Agrário. Para fazer essa análise procura-se fazer uma imersão prévia nos institutos do domínio, posse e propriedade. Discorre sobre questões inerentes à diferença entre domínio e propriedade buscando visualizá-los por meio de uma função dinâmica conjugada por esses três institutos. Finalmente, trata da função social da propriedade através de uma análise socioeconômica, utilizando método crítico dialético, passando pelas presúrias e sesmarias portuguesas, a eclosão do capitalismo e do Estado liberal e das formas de teorização que mudaram a concepção de propriedade a partir dos séculos XVIII e XIX e os meios que foram constituídos para protegê-la.

Palavras-Chave: Direito Agrário. Direitos Humanos. Propriedade. Função Social. Posse.

\begin{abstract}
The article discusses properties' social role as an Agrarian Law principle. In order to do so, it analyzes domain, possession and property rights. It talks about the difference between domains and property throughout the three institutes. Finally, it deals with social role considering a social and economical view, it uses the critical and dialectical method, regarding to presurias and Portuguese sesmarias, the beginning of capitalism and Liberal State, also the theories that changed the idea of property in XVIII and XIX centuries and the ways to protect private property. It uses inductive method.
\end{abstract}

Keywords: Agrarian Law. Human Rights. Property. Social role. Possession.

\footnotetext{
${ }^{1}$ Advogado. Mestre em Direito Agrário pela Universidade Federal de Goiás - UFG, (Brasil). Professor da ESUP-GO.

${ }^{2}$ Advogada. Mestre em Direito Agrário pela Universidade Federal de Goiás - UFG, (Brasil). Professora. E-mail:1r.jordao@me.com
} 


\section{INTRODUÇÃO}

A concepção metodológica na qual se estrutura este artigo tem por base a crítica dialética. Busca-se discutir a função social do imóvel rural no âmbito do Direito Agrário, ocasião em que expõe as teorias mais importantes que amparam a natureza da propriedade com uma abordagem sobre os conceitos de posse, propriedade e domínio, que estruturam o debate e auxiliam na construção de matriz teórica sólida. Acredita-se que somente por meio do enfrentamento das teorias fundamentais será possível trazer o Direito Agrário até o centro do cenário acadêmico, conferindo às questões sociais a ele relacionadas o viés da função social e do aproveitamento econômico sustentável dos imóveis rurais.

Falar sobre a função social da propriedade parece ser dispensável após quase trinta anos da promulgação da Constituição de 1988. Para o Direito Agrário, todavia, continua sendo importante a análise desse instituto, seja sob a forma da concepção de uma função social da propriedade exclusivamente agrária, ou da propriedade intelectual, industrial e suas diversas formas de manifestação.

A função social do imóvel rural, intimamente ligada ao uso da terra, foi elevada a condição de princípio constitucional e tem recebido grande atenção por parte dos juízes e tribunais brasileiros quando enfrentam as questões sobre desapropriação de imóvel rural, expropriações e demais requisitos que condicionam o exercício do direito de propriedade. Entretanto, ainda se questiona o que vem a ser a propriedade.

Sob o aspecto jurídico e da forma em que é exercida hoje, a propriedade tornou-se uma invenção dos séculos XVIII e XIX, que teve o seu embasamento num ideário filosófico para instrumentalizar o sistema econômico capitalista. Pela complexidade do instituto do direito de propriedade, concebido como um dos mais importantes dentre os direitos civis, fazse análise da tríade - domínio, posse e propriedade - a partir das teorias civilistas, com vistas ao desenvolvimento de uma análise socioeconômica da função social da propriedade até a sua incorporação na constituição brasileira enquanto princípio de Direito Agrário. 


\section{DOMÍNIO, PROPRIEDADE E POSSE}

Sob a ótica do Direito Agrário a propriedade pode ser considerada como um de seus pilares de sustentação. Constitucionalmente foi tratada sob o aspecto da função social, elevada pelo legislador a condição de verdadeiro princípio inserido no artigo 170, inciso III, da Constituição Federal de 1988, figurando também no artigo $5^{\circ}$, XXIII, artigo 182, § $2^{\circ}$, e para fins mais específicos do estudo agrarista, nos artigos 184 e 186, tendo por base a propriedade rural.

Para avançar no estudo da função social da propriedade seria necessária uma abordagem conceitual mais ampla, haja vista que a propriedade tem aspectos de natureza civil, agrária, coletiva, urbana, familiar, intelectual, móvel, imóvel. É aberta possibilitando várias intersecções de fundamental interesse para diversos ramos jurídicos, mas que provêm de uma gênese única.

Para iniciar essa incursão indaga-se primeiramente, se seria a propriedade um direito real em sua essência.

Em princípio, seria uma pergunta impertinente, pois a codificação civil como direito real a define. Essa resposta, porém, torna-se um tanto complexa. Embora a civilística clássica a enquadre no âmbito dos direitos reais, alicerçando-a no art. 1.225, do Código Civil, considera-se haver estudos que apontam divergências desta posição, ao passo que se admite que "a propriedade instrumentaliza o domínio" (ARONNE, 1999) e sua oponibilidade erga omnes seria uma característica de direito pessoal e obrigacional, na medida em que, o direito de propriedade é oponível contra todos para o pleno exercício do domínio.

Domínio e propriedade seriam institutos complementares e autônomos, mas as feições atribuídas à propriedade estariam mais condizentes com uma assunção de direitos pessoais, em razão do direito de exclusão, pois o proprietário exclui todos os demais que disputam o direito de usar, gozar e dispor do bem.

Segundo José Serpa de Santa Maria (apud ARONNE, 1999, p. 155) “[...] a propriedade significa que a coisa está reservada somente ao proprietário, de forma que os demais sem direito, não podem subtraí-la ou retê-la, nem perturbá-la ou prejudicar de outro modo o exercício de seu domínio real [...]”3. O conceito revela que o direito de propriedade possui um aspecto interno de feições econômicas e outro externo de feições jurídicas (TEPEDINO, 1997 apud ARONNE, 1999). O aspecto interno revela os poderes que o

\footnotetext{
3 Tradução realizada pelos autores.
} 
proprietário detém sobre a coisa. Poderes titularizados tradicionalmente pelo jus utendi, jus fruendi et jus disponendi que identificam a fluência econômica sobre o bem. As feições externas exibem o poder de exigir a abstenção de terceiros em relação à propriedade titularizada.

As feições interna e externa da propriedade revelam uma dicotomia entre o tratamento que se aplica em relação à coisa e o tratamento que se espera em relação às pessoas. Uma de caráter real e outra de substrato pessoal onde ambas se mostram plenas de elementos inerentes ao domínio e à propriedade sob um mesmo aspecto. Essa abstração conduziu a doutrina a uma bifurcação que ora identifica integralmente o domínio com a propriedade, numa condição de sinonímia, ora identifica o domínio com caráter, conteúdo e profundidade completamente diversos da identificação que se confere à propriedade.

Do ponto de vista civilista, ao se comparar o art. 527, do revogado Código Civil de 1916, com a redação do art. 1.231, do Código Civil de 2002, verifica-se que subsiste a identidade legislada entre domínio e propriedade. Alia-se a esse fato a elevação axiológica da propriedade a uma condicionante presente no ordenamento constitucional que promove uma funcionalização do direito de propriedade, ou seja, admite-se uma utilização condizente com o princípio constitucional da função social.

$\mathrm{Na}$ propriedade, revela-se o exercício de uma relação entre pessoas, na qual o sujeito passivo é indeterminado. A coletividade tem o dever jurídico de se abster de atos que atentem contra a coisa alheia. A relação não se dá entre o proprietário e o objeto, mas entre o sujeito ativo e a coletividade, no sentido de se proteger das perturbações que terceiros possam exercer sobre o objeto.

Uma característica jacente desse fato decorre da reivindicação sob a forma de exercício de pretensão material excludente em relação às pessoas e não em relação direta com o objeto. Haveria neste fato uma prestação, em que o "proprietário é credor de uma obrigação passiva universal" (ARONNE, 1999, p. 94) de dever de abstenção oponível erga omnes, decorrente da intersubjetividade entre os sujeitos da relação e não uma objetividade rigorosamente clássica encontrada na definição de direitos reais. De modo que para Arnoldo Wald (1995) "não existe relação jurídica, no direito de propriedade antes da lesão contra ele perpetrada, mas apenas sujeição da coisa à vontade do proprietário”. Em outras palavras, a propriedade exclui. 
O domínio por sua vez tem por objeto a coisa e as faculdades dela decorrentes, ambas com natureza real, enquanto a propriedade teria natureza pessoal. Ricardo Aronne (1999) faz uma análise histórica do domínio e da propriedade a partir de estudos do romanista Eugène Petit (1892), que se baseando numa comparação entre textos romanos originários e glosas medievais, concluiu que o axioma ius in re aliena atribuído à propriedade, na verdade tratava-se de uma relação obrigacional.

Aronne(1999) apresentou o exemplo sobre o qual o proprietário de um terreno ribeirinho deveria tolerar o uso público de suas margens. Concluiu que esta seria uma obrigação de suportar e que, por não se tratar de uma servidão, não se inseriria no âmbito real. O proprietário poderia usar, fruir e dispor da integralidade do bem, revelando possuir completo domínio sobre o mesmo (domínium est in plena re potestas), apesar de não poder opor seu direito in personam, para obstar o uso público da referida margem. Assim, haveria uma funcionalização da propriedade e não do domínio, cuja oposição deste estaria congelada pela propriedade (ARONNE, 1999).

Outra maneira de se observar essa relação, consistiria no exemplo da exploração de jazidas de minérios em terras particulares. Neste caso, haveria uma limitação ao exercício da propriedade, ao se admitir que terceiros devidamente licenciados pelo órgão da União pudessem adentrar ao imóvel e explorá-lo mediante o pagamento ao proprietário dos royalties e indenizações correspondentes à exploração mineraria. Em função de uma limitação ao uso da propriedade, decorrente de uma reserva para a União dos recursos minerais, prevista no art. 20, IX, da Constituição Federal, haveria de se concluir, que o proprietário estaria recaindo em uma obrigação de suportar a limitação, mediante um ressarcimento pecuniário.

O exemplo ilustra os limites intersubjetivos da obrigação passiva universal de que outros, inclusive o ente público, se abstenha de perturbar o exercício em substância do direito, de usar, fruir e dispor da coisa.

Há de se concluir que o problema de limitação ao exercício da propriedade não é objeto de direito real, ao passo que os poderes de domínio (usar, fruir e dispor) estão todos titularizados pelo senhorio, que poderá exercê-los livremente em relação à coisa, inclusive transferindo-os a terceiros, porém guardando a limitação imposta pelo ente público ao exercício da propriedade.

O domínio, em sua natureza, é um direito real por excelência, embora não integre a codificação brasileira com esse sentido. Parte das relações existentes entre o indivíduo e o 
objeto de onde emerge o exercício dos direitos dominiais. Apesar de ser uno e indivisível, em razão do princípio da elasticidade, o domínio pode se desdobrar em parcelas. Assim, é possível desdobrar o jus fruendi et utendi em favor do usufrutuário e preservar o jus disponendi em favor do titular do domínio, que continuaria a exercer a propriedade. Por ser uno e indivisível não poderia concorrer dois domínios sobre a mesma coisa, pois essa proibição deriva da exclusividade dos direitos reais.

Na relação condominial a pluralidade de pessoas equivale a apenas um polo em relação à coisa, que não comportaria mais de um domínio encabeçado por pessoas diversas. Haveria uma limitação ao exercício da propriedade que incidiria sobre os condôminos considerados entre si, e destes em relação ao objeto, mas não haveria limitação ao exercício da propriedade considerando-os em sua coletividade (condomínio), como sujeito de direito em relação à res.

Em um condomínio cujo bem é dado em usufruto haveria condomínio no respectivo exercício da parcela de domínio destacada em favor dos condôminos, mas não haveria copropriedade, pois nenhum usufrutuário seria proprietário, em razão da instrumentalização desta com o domínio. O titular do domínio ao destacar o jus utendi et jus fruendi em favor do usufrutuário estaria a exercer a propriedade titularizada sob o domínio, enquanto os condôminos a exteriorizariam através da posse, tal qual a elasticidade do domínio destacado. Para alguns, estar-se-ia no âmbito do domínio direto e do domínio indireto, cuja análise não será realizada neste trabalho.

Rudolf von Ihering mencionou em sua teoria objetiva, ser a posse a exteriorização da propriedade e a visibilidade do domínio, o poder de dispor da coisa. Sua natureza jurídica seria de direito cuja causa derivaria de um fato de utilização econômica da propriedade tendo lugar ao lado dos direitos reais. Por outro lado, Savigny veria na posse, simultaneamente fato e direito sobre a qual se exteriorizaria o poder daquilo que pertence ao possuidor, incluindo-se por natureza, na classificação de direitos pessoais (MONTEIRO, 2005).

Savigny parte da noção apresentada pelos romanos de que a posse seria adquirida por meio de conjunção entre o corpus e o animus. Para que houvesse posse, bastaria que existisse também a vontade de possuir. Portanto, despiciendo seria a apreensão material da coisa ou a vontade de realizar a apreensão. O possuidor seria reconhecido pelo comportamento de proprietário da coisa por ele detida. Aquele que age como se dono fosse e que nega o reconhecimento do direito exclusivo de terceiro seria caracterizado como possuidor (ZELEDÓN, 2013). 
Já Ihering refuta o caráter conferido ao animus domini ao animus possidendi, por ele compreendidos como estados psicológicos do sujeito, portanto, incapazes de produzir reflexos no mundo exterior. Ihering busca um critério finalista e objetivo que se colocasse de acordo com seu posicionamento em relação ao Direito, no sentido de que o corpus consiste na relação de exterioridade dada à relação exterior que vincula o domínio à propriedade (ZELEDÓN, 2013).

Novamente nota-se a divergência doutrinária relativa ao caráter objetivo (Ihering) e subjetivo (Savigny) em relação à posse, como também ocorreu em relação ao domínio e propriedade, mas ao contrário destes, a posse sempre mereceu maior atenção por parte da doutrina.

No sentido da classificação jurídica, conforme mencionado alhures, há de se ver no domínio a natureza de direito real e, na propriedade a natureza de direito pessoal, embora a lei assim não entenda, tanto que a codificação civil excluiu o domínio da legislação material e deu status de direito real à propriedade.

Enquanto tem o domínio um caráter estático, a propriedade teria um caráter dinâmico, pois parcela do domínio poderia ser destacada ao exercício da propriedade. Por esse caráter dinâmico a ela conferido, entende-se que o domínio se tem, ao passo que a propriedade se exerce, enquanto a posse integra ambos.

Sob esse aspecto a posse estaria confirmando a teoria objetiva de Ihering como elemento de exteriorização dos direitos de domínio e propriedade, sendo irrelevante dizer, se haveria de se tratar de posse justa ou injusta.

Seguindo esse raciocínio, a posse seria elemento estático de integração que exterioriza os poderes inerentes ao domínio e ao exercício da propriedade. Assim, não haveria de se falar em posse direta e posse indireta. A posse seria sempre direta, pois o que se chamaria de posse indireta na verdade seria elemento da propriedade. Posse indireta, nas palavras de Gondin Neto, é "mera ficção"4.

Para o Direito Agrário, a discussão sobre a posse direta e indireta é irrelevante, como muito bem afirmou o Prof. Benedito Ferreira Marques(2015, p. 48), "Inexiste posse agrária indireta[...]" haja vista que somente com a posse se viabiliza as atividades agrárias.

\footnotetext{
4 “Observa-se mais que, no terreno puramente doutrinário, há quem não considere como verdadeira posse a indireta, só merecendo tal conceituação a direta. Assim, entre nós, sustenta o Prof. Gondin Neto que a posse indireta constitui mera ficção, cuja importância não vai além da possibilidade de recorrer seu titular às ações possessórias para reprimir atos atentatórios da posse do verdadeiro possuidor" (GONDIN NETO, apud MONTEIRO, 2005, p. 28).
} 
Por essa característica peculiar a posse agrária ganha relevância sobre o título de propriedade (MARQUES, 2015).

Nesse sentido há de se convir que a posse agrária seja uma legítima exteriorização do exercício da propriedade, mesmo que de forma aparente. Na posse agrária há uma presunção da titularidade da terra ou do exercício regular da propriedade. Nela se encontra o exercício ou destaque do domínio sobre a propriedade de modo que possibilita a efetiva utilização da terra.

As características da posse agrária na sistemática do direito latino-americano permitiram o desenvolvimento de conceito que alia a presença direta do possuidor no imóvel à estreita relação entre a terra e o trabalho humano. Neste sentido, a posse agrária apresenta características absolutamente diversas daquelas aplicáveis à posse civil, porquanto aquela é concebida de modo autônomo como forma de exercício de bens agrários com vistas à aquisição da propriedade por meio da usucapião agrária (ZELEDÓN, 2013, p. 234-235)

Os três institutos são autônomos e complementares, pois mesmo que o possuidor não exerça a propriedade ou detenha o domínio, ele congrega uma condição de aparência de exercício desses direitos através da posse, inclusive por uma condição de expectativa de aquisição tanto do domínio quanto da propriedade. Desta forma, se justifica a afirmação de que na posse se integram o domínio e a propriedade, mesmo que apenas aparentemente.

Exemplo desse fato pode ser observado através da usucapião de imóvel rural. Situação na qual o usucapiente detém a posse direta da terra, porém as execuções decorrentes de obrigações propter rem inerentes ao imóvel incidem passivamente sobre àquele em cujo nome o bem está transcrito no registro imobiliário. Tanto que através da ação reivindicatória o titular do imóvel busca reaver a posse, ao passo, que por meio de defesa admite-se a exceção de usucapião, sobre a qual se prolatará uma sentença de natureza mista: "declaratória de domínio, constitutiva de propriedade e mandamental para efeitos registrais" (ARONNE, 1999, p. 79).

A posse dá essa aparência de regularidade material ao bem. Caso domínio e propriedade fossem sinônimos, como apresentam alguns autores, o posseiro ou usucapiente teria meios para gravar o bem em ônus real, fato que resulta impossível devido a ausência de título. Eis que o posseiro ou usucapiente pode defender a sua posse, pode exercer os direitos de propriedade, usar, fruir e eventualmente até dispor do imóvel, mas sem a aquisição do título dominial por meio de uma declaração judicial a propriedade não se consolida nas mãos do posseiro ou usucapiente. 
Exemplo claro dessa situação ocorre na legitimação de posse de imóvel rural sobre terras devolutas, regulamentada na Lei $\mathrm{n}^{\circ}$ 6.383/76. Neste caso o posseiro, cumprido os requisitos que a lei determina, após um ano de posse comprovada sobre o imóvel, poderá pleitear uma licença de ocupação regular cuja duração é de quatro anos. Depois de cinco anos de ocupação do imóvel e cumprido os demais requisitos legais, o ocupante poderá adquirir o título dominial pelo valor da terra nua.

O artigo 30 desta lei garante que o detentor da licença de ocupação terá acesso ao crédito rural e que as obrigações assumidas pelo ocupante frente à instituição financeira serão garantidas pelo INCRA e que no caso de inadimplência, a licença seria cancelada e o imóvel alienado para ressarcimento do que houvera segurado. Neste caso o posseiro titulariza o direito de propriedade, mas não o domínio, que continua sendo da União. Apesar da previsão de que a terra possa ser gravada como garantia real de financiamento rural, mediante a apresentação da licença de ocupação, elemento essencial de destaque do domínio sobre a propriedade (possibilidade de gravar o bem), quem na verdade garante a dívida é a União por meio do INCRA.

Analisando esse fato, relembro o comentário em sala de aula do Prof. Benedito Ferreira Marques, dizendo que durante os longos anos em que trabalhou no setor de crédito rural do Banco do Brasil, jamais presenciou o INCRA como garantidor de crédito com base em licença de ocupação. Para implementar o acesso ao crédito foi necessário criar meios que possibilitassem a utilização da produção rural como garantia do empréstimo, fato que se deu através de iniciativas estaduais (MARQUES, 2015).

\section{FUNÇÃO SOCIAL DA PROPRIEDADE RURAL}

Em princípio, falar sobre função social da propriedade implicaria discutir o interesse coletivo.

Ricardo Zeledón Zeledón (2013) concebe o Direito Agrário como direito humano de terceira dimensão, vinculado ao primado da solidariedade, que se desenvolve como produto do processo econômico capitalista diante da incapacidade do Direito Privado para solucionar as questões vinculadas à agricultura e ao campo.

Neste mister, a função social da propriedade consistiria no direito de todos “" [...] 
aquellos que no tienen la propriedade, o la tienen en forma insuficiente, gozando de la capacidad de poder poner la misma en condiciones de producción, de ser dotados por el Estado de ella" (ZELEDÓN, 2013, p. 82).

Para fins de imóvel rural, a Constituição brasileira, no artigo 186, diz o que se segue:

\footnotetext{
Art. 186. A função social é cumprida quando a propriedade rural atende, simultaneamente, segundo critérios e graus de exigência estabelecidos em lei, aos seguintes requisitos:

I - aproveitamento racional e adequado;

II- utilização adequada dos recursos naturais disponíveis e preservação do meio ambiente;

III - observância das disposições que regulam as relações de trabalho;

IV - exploração que favoreça o bem-estar dos proprietários e dos trabalhadores.
}

A leitura do artigo possibilita dividir em dois grupos os requisitos para o cumprimento da função social da propriedade rural. $\mathrm{O}$ primeiro deles com os incisos primeiro e segundo, o qual pode ser sintetizado como "o respeito à terra". O segundo grupo constituído pelos incisos terceiro e quarto, correspondentes ao "respeito ao homem". De modo, que o cumprimento da função social da propriedade rural se daria quando o imóvel é explorado com vistas ao respeito a terra e o respeito ao homem.

Nos termos em que a norma é redigida, permite indagar se a função social prevista no artigo 186 condicionaria ou não a propriedade rural. A resposta a essa indagação é afirmativa e encontra-se de maneira mais clara no Estatuto da Terra: “Art. $2^{\circ}$ É assegurado a todos a oportunidade de acesso à propriedade da terra, condicionada pela sua função social, na forma prevista nesta lei” (Lei n. 4.504, de 1964).

Em relação ao imóvel considerado em si mesmo, a função social o adjetiva ou o valoriza. Em relação ao direito, a função social condiciona, funcionaliza. Assim, dizer que o imóvel rural possui uma função social ou exerce uma função social, seria um valor atribuído a este imóvel. Já dizer que o exercício do direito de propriedade sobre o imóvel é condicionado ao cumprimento da sua função social, é bem diferente. A funcionalização do direito de propriedade corresponde a uma limitação imposta pelo Estado através de uma norma cogente e de substrato constitucional, hoje consagrado no artigo $5^{\circ}$, inciso XXIII, e artigo 186 da Constituição Federal de 1988.

Conforme afirmado anteriormente, a função social da propriedade rural pode ser sintetizada em duas frases: "respeito a terra" e "respeito ao homem". Essa distinção vem das fontes materiais, pois se trata de um processo sociocultural e histórico pelo qual se vivencia o 
caráter dinâmico da compreensão da função social da propriedade, esse critério também acompanharia essa evolução.

Na linha histórica do direito lusitano, Virginia Rau (1945), em sua tese de doutoramento relata que na Idade Média peninsular portuguesa havia pelo menos dois meios de aquisição de direitos sobre a gleba, por direito de conquista (presúrias) ou por sesmarias. Se a finalidade econômica e social da presúria ${ }^{5}$ era o repovoamento e arroteamento $^{6}$ das terras conquistadas, nada mais lógico supor que o cultivo originasse um verdadeiro direito.

A terra erma, vaga, apropriada ou doada para ser posta em cultivo, se permanecesse inculta era retirada ao possuidor para ser entregue a quem a lavrasse. "Só o labor garantia a posse" (RAU, 1945, p. 36). Esse era o entendimento que prevalecia entre os séculos IX e XIII na península ibérica. A função social da propriedade rural era laborar a terra, cultivando-a de modo que permitisse alimentar a população e fomentar núcleos de povoamento, principalmente no Norte de Portugal.

Mesmo depois de adquiridas as glebas, a apropriação particular deveria guardar limites com os interesses da comunidade local. A terra improdutiva era nociva à coletividade e deveria ser redistribuída por sesmeiros ${ }^{7}$. Do mesmo modo, não se permitia a ocupação indiscriminada da terra apenas para fins de cultivo, pois havia também a necessidade de preservação das matas para uso da coletividade (RAU, 1945).

A inobservância destes costumes implicaria em reclamações dos Conselhos das vilas ao rei de Portugal $^{8}$. A terra exercia uma função social voltada a sobrevivência de uma comunidade. Não se cogitava na ociosidade da terra. O instituto das sesmarias surgiu em Portugal justamente neste contexto, para redistribuir as terras conquistadas e não trabalhadas. A porção de terra era marcada pelo arado e tinha a medida que podia ser trabalhada, pois a

\footnotetext{
${ }^{5}$ Terras tomadas por forças militares. Também pela ocupação de charcos e alagados.

${ }^{6}$ Desbravamento, cultivo.

7 "No Algarve, em 1392, o concelho de Tavira insurgiu-se contra aqueles que tendo recebido sesmarias as não lavravam e exigiam uma certa prestação daqueles que o queriam fazer, o que ocasionava não ter a vila aquela abundância de pão que poderia lograr se tais terras fossem semeadas; logo o conselho pediu e obteve autorização para prover a que aqueles matos assim dados, e que não eram cultivados, o pudessem ser por quantos os quisessem romper e arrotear" (RAU, 1945, p. 126-127).

8 "Portalegre queixou-se, então, que o sesmeiro não guardava a mata da vila - que era muito proveitosa aos moradores porque nela encontravam paus para as suas vinhas a pouca distância da vila - e a dava de sesmaria; os procuradores lembraram ao soberano que já em tempos, quando estivera em Estremoz, lhe tinham pedido, e obtido, que fosse impedido aos caçadores de a queimarem e danificarem. 'E agora Senhor em vez de a dita mata sser guardada vosso sesmeiro a da de sesmaria o que o Senhor em vida vossa nom sse acha que de sesmaria desse nem a Rezãão nom ho comssemte sseer dada' por ser tão proveitosa aos moradores da vila que já não tinham onde ir buscar madeira senão com mui grande trabalho por "híj nom aveer outro lugar homde os vãão colher" (RAU, 1945, p. 128-129).
} 
ociosidade da terra era tida como nociva à comunidade, portanto, havia de ser distribuída para que a todos beneficiasse (RAU, 1945).

Com a expansão do mercantilismo entre os séculos XV e XVIII tornou-se necessário criar uma base consumidora para a venda de mercadorias. A criação de uma demanda por produtos e quinquilharias emergiu das entranhas do comércio mercantilista para sustentar a base de uma teoria sobre acumulação de riquezas.

Para proporcionar o processo de industrialização da Grã-Bretanha, iniciado no final do século XVIII tornou-se necessária a criação de mão de obra livre e desembaraçada (leia-se em regime de semi-escravidão, tão bem retratada pelo romancista inglês Charles Dickens em “Tempos Difíceis”) (FAORO, 1979).

O problema agrário era questão fundamental em 1780, pois enquanto o homem laborasse na terra não haveria nem mão de obra e nem consumo, capaz de fomentar o processo industrial emergente (GUIMARÃES, 1981). Assim eclodiu a dupla revolução liberal burguesa, pois enquanto a base econômica era construída na Grã-Bretanha os instrumentos teóricos da política liberal, as técnicas e o modelo da codificação eram fornecidos pelos filósofos franceses, tornando-se inconcebível pensar o processo de Revolução Industrial sem o subsídio teórico da Revolução Francesa de 1789.

Neste contexto, embasando-se no pensamento liberal, e principalmente nos contratualistas, dentre eles John Locke, surgiu a ideia de propriedade calcada no direito excludente, absoluto. Verdadeira concepção da liberdade, pois a partir do século XIX a ideia de apropriação de uma parcela do globo terrestre chegaria ao ponto de poder considerar a possibilidade de destruí-la, depredá-la, se quer usá-la de modo sustentável.

A propriedade tornou-se absoluta apoteose do discurso da liberdade, entorno do qual se armou o Estado com a codificação civil napoleônica, modelo das demais codificações que iriam edificar a propriedade como o direito individual mais importante, que necessitava ser sustentado pelo Estado liberal na sua formação constitucional, a exemplo do que dispôs a Constituição de Cádis: “Artículo 4. La nación está obligada a conservar e proteger por leyes sabias e justas la libertad civil, la proprietad, y los demás derechos legítimos de todos los individuos gue la componen" (ESPANHA, 1812) ${ }^{9}$.

A partir do século XIX, a terra que antes servia de sustento ao homem passou a ser considerada como riqueza individual dentro de um processo de acumulação de capital.

\footnotetext{
${ }^{9}$ Constituição espanhola de 1812 apud MARÉS, op. cit., p. 33.
} 
Chegava-se ao fim o instituo das sesmarias, pois a sua função distributiva não era mais necessária. A função social da propriedade agrária, a partir do século XIX era possibilitar a acumulação de riqueza, inclusive através da exclusão do homem da cadeia produtiva agrária, expulsando-o para as cidades ou criando condições para que se estabelecesse um regime de semiescravidão, em que o trabalho da massa era remunerado com o mínimo necessário para sobrevivência e manutenção da chamada força de trabalho livre (MARTINS, 1979).

Embasando-se no discurso político-econômico da dupla revolução (Revolução Industrial e Revolução Francesa), a Constituição Política do Império do Brasil de 1824, confirmou a adoção do sistema engendrado para acumulação de capital, tendo por base o fomento ao latifúndio. Consagrava o absolutismo da propriedade, sobretudo da propriedade agrária, antes concebida como direito natural, agora trabalhada para ser blindada pelo positivismo emergente das codificações civilistas ${ }^{10}$.

O rígido controle sobre as terras era condição sine qua non para gestar o processo de acumulação do capital, pois se o governo permitisse que o vasto território brasileiro fosse ocupado por homens livres aptos a cultivar as terras nacionais como suas propriedades, seria como se prolatasse a sentença de morte aos interesses dos barões do café e dos remanescentes da sociedade escravocrata. Neste jardim floresceu as páginas de alguns dos mais sangrentos e vergonhosos conflitos agrários de nossa história: Canudos e Contestado (FAORO, 1979).

Desde o Brasil imperial até a Primeira República, a desapropriação era exceção que necessitava regulamentação por lei infraconstitucional, além de exigir do Estado que indenizasse o proprietário pelo bem expropriado. Mesmo no caso da subutilização da terra o Estado premiaria o expropriado, comprando-lhe a propriedade sob outro título, agora denominado indenização (MARTINS, 1979).

Enquanto o constitucionalismo do século XIX absolutivizava a propriedade, por outro lado, a Constituição do México, de $1917^{11}$, dava um caráter nacional à terra já que afirmava ser a propriedade das terras e águas pertencente originalmente à nação mexicana.

\footnotetext{
${ }^{10}$ Constituição Política do Império do Brasil - 1824. "Art. 179 A inviolabilidade dos direitos civis e políticos dos cidadãos brasileiros, que tem por base a liberdade, a segurança individual e a propriedade, é garantida pela Constituição do Império, pela maneira seguinte: [...] inciso XXII - é garantido o direito de propriedade em toda a sua plenitude. Se o bem jurídico legalmente verificado exigir o uso e emprego da Propriedade do Cidadão, será ele previamente indenizado do valor dela. A lei marcará os casos em que terá lugar esta única exceção, e se dará as regras para se determinar a indenização".

${ }^{11}$ Constitucion Politica de los Estados Unidos Mexicanos, 1917: ARTICULO 27 - La propiedad de las tierras y aguas comprendidas dentro de los límites del territorio nacional corresponde originariamente a la Nación, la cual ha tenido y tiene el derecho de transmitir el dominio de ellas a los particulares constituyendo la propiedad privada.
} 
O constituinte mexicano se afastou consideravelmente do caráter individualista para consagrar a possibilidade de o Estado definir critérios de propriedade que levassem em conta o interesse público e social ademais de regulamentar a utilização dos recursos ambientais e a distribuição equitativa da riqueza pública (ZELEDÓN, 2013, p. 224).

Segundo Carlos Frederico Marés, a Constituição Mexicana diferenciava duas formas de intervenção na propriedade:

\begin{abstract}
[...] por um lado reconhecia a desapropriação que somente pode se dar por razões de utilidade pública e mediante indenização, existente desde os tempos do nascimento do liberalismo; por outro não reconhece como propriedades áreas que não cumpram os preceitos necessários a seu exercício, quando, então, se dá a intervenção para regular o aproveitamento dos elementos naturais suscetíveis de exploração e a justa e equitativa distribuição da riqueza. Neste item inclui a divisão do latifúndio e o direito de indígenas, coletivamente à terra e a água. Estabelece uma larga lista de proibições às pessoas jurídicas de adquirirem terrenos rurais e os possuírem, entre os quais, a Igreja, as sociedades comerciais por ações e os bancos. Veda, ainda, acesso ao Judiciário aos proprietários afetados por atos que chama de restituição, que são, na realidade, anulação de títulos outorgantes de propriedades originárias concedidos contra posse preexistentes (MARÉS, 2003, p. 94).
\end{abstract}

Enquanto a Constituição Mexicana representava exceção à regra ao absolutismo da propriedade, o extremo grau de concentração de terras na mão de poucos se tornaria nocivo ao processo de acumulação de riquezas. O Estado liberal precisaria reagir para novamente integrar ao sistema produtivo a massa de pobres e miseráveis excluídos que ocupavam as cidades. Uma pequena correção era necessária para continuar o percurso da máquina capitalista.

Sob os princípios do Walfare State emergia uma nova ordem que precisava se preocupar com o mínimo necessário para o bem estar da massa de súditos do Estado, antes desassistidos e impossibilitados de trabalho e consumo, claro obstáculo ao processo de acumulação de capital no qual as Nações estavam imbuídas. O estado do bem estar social era o prenúncio de uma nova ordem constitucional liberal, que haveria de declarar: que a terra era privada, que era absoluto o direito de propriedade, mas que excepcionalmente esse direito poderia ser limitado, pois a propriedade abrigaria uma função social. O arauto dessa nova ordem foi a Constituição de Weimar de 1919, cujo artigo 153 inseria a consagrada fórmula "A propriedade obriga" e que seu uso deve atender às necessidades comuns ${ }^{12}$.

\footnotetext{
12 DEUTSCHLAND, Die Verfassung des Deutschen Reiches (Weimarer Reichsverfassung). Artikel 153. (1) Das Eigentum wird von der Verfassung gewährleistet. Sein Inhalt und seine Schranken ergeben sich aus den Gesetzen. (2) Eine Enteignung kann nur zum Wohle der Allgemeinheit und auf gesetzlicher Grundlage vorgenommen werden. Sie erfolgt gegen angemessene Entschädigung soweit nicht ein Reichsgesetz etwas anderes bestimmt. Wegen der Höhe der Entschädigung ist im Streitfalle der Rechtsweg bei den ordentlichen
} 
No Brasil, a propriedade continuava plena e uma pequena flexibilização foi admitida na Constituição de 1934, possibilitando a lei alterar o conteúdo da propriedade privada sujeitando-a ao interesse comum e social (MARÉS, 2003). As discussões de maior relevância somente ganhariam fôlego a partir da promulgação do Estatuto da Terra em 1964, sob a égide do Governo Militar, que sucumbiu às pressões de interesses internacionais, sobretudo dos Estados Unidos, que viam no conflito agrário emergente campo fértil para a propagação de ideais socialistas e obstáculo para a expansão do capitalismo. Questão delicada de se lidar no auge da antiga guerra fria.

Somente a partir da Constituição Federal de 1988, pode-se dizer que realmente foi iniciado um debate sobre a propriedade e sua função social. Na opinião do professor Carlos Frederico Marés (2003), houve uma tentativa de se fazer que o proprietário da terra cujo uso não cumprisse a função social não pudesse se utilizar dos institutos protetivos do Direito, para reaver a terra de quem a fizesse cumprir a função social. Porem essa intenção foi minada pelos latifundiários que construíram armadilhas no texto constitucional de modo a dar-lhe a beleza de um "poema".

O artigo 184 manteve a premiação ao uso danoso da propriedade, ou em outras palavras, a venda ao Estado do imóvel rural que não estivesse cumprindo a sua função social, pois o Estado, para dar destinação adequada ao imóvel, deveria indenizar o proprietário que descumpre com a condição preconizada pela lei. O artigo 185 trouxe ainda os imóveis insuscetíveis de desapropriação para fins de reforma agrária, ou seja, a pequena e média propriedade rural, assim definidas em lei, desde que seu proprietário não possuísse outra e que fosse a propriedade produtiva. Sobre esta, observa-se que índice de produtividade deveria ser visto dentro do contexto da função social, ou seja, conjugado com os demais requisitos do artigo 186. Uma propriedade com altos índices de produtividade pode também ser extremamente danosa, quando essa propriedade esgota ou exaure a terra, desmata, utiliza-se de trabalho escravo, destrói nascentes e matas ciliares, polui o meio ambiente.

Benedito Ferreira Marques defende que a produtividade integra a função social, assim como a proteção ao meio ambiente, o cumprimento das obrigações tributárias, trabalhistas, dos índices de produtividade com respeito à terra, dentre outros. Tais requisitos

Gerichten offen zu halten, soweit Reichsgesetze nichts anderes bestimmen. Enteignung durch das Reich gegenüber Ländern, Gemeinden und gemeinnützigen Verbänden kann nur gegen Entschädigung erfolgen. Eigentum verpflichtet. Sein Gebrauch soll zugleich Dienst sein für das Gemeine Beste. (sem grifo no original). 
constituem o que ele chamou de Teoria dos Leques $^{13}$, em que se imagina que a propriedade estaria no centro, e a sua volta, tais quais às pás de um moinho se encontrariam os elementos dinâmicos que cumpririam a função social da propriedade.

\section{CONCLUSÃO}

A função social da propriedade hoje é vista como uma necessidade de sobrevivência da humanidade, através do uso racional dos recursos naturais. Neste mister, o Direito Agrário integra o plano de direitos humanos de terceira dimensão, ao lado dos direitos ao desenvolvimento, ao meio ambiente ecologicamente equilibrado, à segurança alimentar e à paz.

O entendimento do Direito Agrário orientado pela aplicação do princípio da função social da propriedade enquanto condicionante do direito à propriedade possibilita sua rediscussão e reconstrução. Os institutos agrários, de modo geral, devem se voltar ao atendimento das duas vertentes que integram a função social.

A concepção liberal de propriedade não mais pode persistir no século XXI. Assim, para que a norma constitucional prevista no artigo 186 possa ter eficácia é necessária uma verdadeira mutação constitucional, a partir de uma interpretação voltada aos princípios, que busque uma harmonização dos conflitos existentes para desmontar as armadilhas deixadas pelas forças do poder latifundiário que influenciaram na elaboração do texto legal.

A função social é um conceito socioeconômico. Antes mesmo de integrar o Direito ele foi construído através de uma justificação teórica. O Direito atua como instrumento de legitimação dos fatores que circundam a propriedade. A ideia de cumprimento da função social da propriedade deve deixar de ser mera valoração ao direito de propriedade, passando a integrá-lo como condição de sua existência.

A efetivação dessa condição passa essencialmente pela necessária revisão do pensamento dominante nos tribunais, aptos a interpretar a Constituição e integrar o texto de forma que não continue sendo objeto de apreciação literária, mas de eficácia social, de modo que a exploração da propriedade, principalmente da propriedade agrária, possa se pautar pelo respeito à terra e ao homem.

\footnotetext{
${ }^{13}$ Nota dos autores: Trata-se de informação verbal em sala de aula, ao comentar que após algumas reflexões revisaria a sua concepção sobre a função social da propriedade.
} 


\section{REFERÊNCIAS}

ARONNE, Ricardo. Propriedade e domínio: reexame sistemático das noções nucleares de direitos reais. Rio de Janeiro: Renovar, 1999.

BORGES, Paulo Torminn. Institutos básicos do direito agrário. 11. ed. rev. São Paulo: Saraiva, 1998.

BRASIL. Constituição Política do Império do Brasil, de 25 de março de 1824. Disponível em: <http://www.planalto.gov.br/ccivil_03/constituicao/constitui\%C3\%A7ao24.htm>. Acesso em: 20 ago. 2016.

Lei 4.504, de 30 de novembro de 1964. Dispõe sobre o Estatuto da Terra e dá outras providências. Diário Oficial da União, de 31/11/1964.

Lei $\mathrm{n}^{\circ}$ 9.279, de 14 de maio de 1996. Regula direitos e obrigações relativos à propriedade industrial. Diário Oficial da União, de 15 maio 1996. Disponivel em: <http://www.planalto.gov.br/ccivil/leis/L9279.htm>. Acesso em: 20 ago. 2016.

DEUTSCHLAND, Die Verfassung des Deutschen Reiches (Weimarer Reichsverfassung). Disponível em: <http://www.documentarchiv.de/wr/wrv.html>. Acesso em: 22 set. 2016.

ESPANHA. Constituición de Cádis. 1812. Disponível em: <http://www.congreso.es/docu/constituciones/1812/ce1812.pdf>. Acesso em: 22 set. 2016.

FAORO, Raimundo. A direção da economia no Segundo Reinado. In: Os donos do poder: formação do patronato político brasileiro. Porto Alegre: Editora Globo, 1979, p.399-440.

O Renascimento Liberal e a República. In: Os donos do poder: formação do patronato político brasileiro. Porto Alegre: Editora Globo, 1979, p.441-494.

GUIMARÃES, Alberto Passos. Quatro séculos de latifúndio. 5. ed. Rio de Janeiro: Paz e Terra, 1981.

LASSALLE, Ferdinand. A essência da Constituição. 7. ed. Rio de Janeiro: Lumen Juris, 2007, Coleção Clássicos do Direito.

LISITA, Cristiane. Fundamentos da propriedade rural: conflitos agrários e justiça social. Belo Horizaonte: Mandamentos, 2004.

LOCKE, John. Segundo tratado sobre o governo civil: ensaio sobre a origem, os limites e os fins verdadeiros do governo civil. Tradução de Magda Lopes e Marisa Lobo da Costa. Petrópolis : Vozes, 1994 - (Coleção clássicos do pensamento político), cap. V. p. 97-112.

MARÉS, Carlos Frederico. A função social da terra. Porto Alegre: Sérgio Antônio Fabris 
Editor, 2003.

MARQUES, Benedito Ferreira. Direito agrário brasileiro. 11. ed. rev. e ampl. São Paulo: Atlas, 2015.

MARTINS, José de Souza. A produção capitalista de relações não capitalistas de produção: $o$ regime de colonato nas fazendas de café. In: O cativeiro da terra. São Paulo: Livraria Editora Ciências Humanas, 1979, p. 7-93.

MEXICO. Constitucion política de los Estados Unidos Mexicanos. Edition Oficial. Imprenta de La Secretaria de Gobierno. México, 1917.

MONTEIRO, Washington de Barros. Curso de direito civil. 36. ed . São Paulo: Saraiva, 2005, v. 3.

OLIVEIRA, Humberto Machado de. Princípios de direito agrário na constituição vigente. $2^{\mathrm{a}}$ tir. Curitiba: Juruá, 2006.

RAU, Virgínia. Sesmarias medievais portuguesas. Lisboa: Presença, 1982.

ROUSSEAU, Jean-Jacques. Discurso sobre a origem e os fundamentos da desigualdade entre os homens. Brasília: Editora Universidade de Brasília/São Paulo: Ática, 1989.

WALD, Arnoldo. Direito das coisas. 10. ed. São Paulo: RT, 1995.

WOOD, Ellen Meiksins. As origens agrárias do capitalismo. Tradução de Lígia Osório Silva. Revista Crítica Marxista, n. 10, ano 2000. São Paulo: [s.n]. p. 4-23. Disponível em: <http://www.ifch.unicamp.br/criticamarxista/arquivos_biblioteca/artigo6612_merged.pdf >. Acesso em: 10 set. 2016.

ZELEDÓN, Ricardo Zeledón. Derecho agrario contemporáneo. 2. ed. rev. atual. Curitiba: Juruá, 2013. 